\title{
Proliferative kidney disease (PKD) of rainbow trout: temperature- and time-related changes of Tetracapsuloides bryosalmonae DNA in the kidney
}

\author{
K. BETTGE, H. SEGNER, R. BURKI, H. SCHMIDT-POSTHAUS and T. WAHLI* \\ Centre for Fish and Wildlife Health, Institute of Animal Pathology, University of Berne, Laenggassstrasse 122, \\ P.O. Box 8466, 3001 Berne, Switzerland
}

(Received 21 November 2008; revised 29 Fanuary 2009; accepted 29 Fanuary 2009; first published online 14 April 2009)

S UMMAR Y

Proliferative kidney disease (PKD) of salmonids, caused by Tetracapsuloides bryosalmonae, can lead to high mortalities at elevated water temperature. We evaluated the hypothesis that this mortality is caused by increasing parasite intensity. T. bryosalmonae-infected rainbow trout (Oncorhynchus mykiss) were reared at different water temperatures and changes in parasite concentrations in the kidney were compared to cumulative mortalities. Results of parasite quantification by a newly developed real-time PCR agreed with the number of parasites detected by immunohistochemistry, except for very low or very high parasite loads because of heterogenous distribution of the parasites in the kidney. Two experiments were performed, where fish were exposed to temperatures of $12,14,16,18$ or $19{ }^{\circ} \mathrm{C}$ after an initial exposure to an infectious environment at $12-16{ }^{\circ} \mathrm{C}$ resulting in $100 \%$ prevalence of infected fish after 5 to 14 days of exposure. While mortalities differed significantly between all investigated water temperatures, significant differences in final parasite loads were only found between fish kept at $12{ }^{\circ} \mathrm{C}$ and all other groups. Differences in parasite load between fish kept at $14{ }^{\circ} \mathrm{C}$ to $19{ }^{\circ} \mathrm{C}$ were not significant. These findings provide evidence that there is no direct link between parasite intensity and fish mortality.

Key words: Tetracapsuloides bryosalmonae, real-time PCR, temperature, proliferative kidney disease, rainbow trout.

\section{INTRODUCTION}

Proliferative kidney disease (PKD) is a parasitic disease of salmonid fish (Canning et al. 1999; Okamura et al. 2001). The aetiological agent of PKD is the myxozoan parasite Tetracapsuloides bryosalmonae (Myxozoa: Malacosporea) (Canning et al. 1999, 2002). Fish are infected by parasite spores released from bryozoans which are the invertebrate host of the parasite (Feist et al. 2001). T. bryosalmonae infects the fish through skin and gills (Longshaw et al. 2002) and afterwards invades inner organs, with the kidney being the main target organ (Ferguson and Ball, 1979; Ferguson, 1981; Clifton-Hadley et al. 1986). Infection of the latter organ can lead to a massive granulomatous infiltration and proliferation of the interstitial tissue, hence the name of the disease (Ferguson and Ball, 1979; Ferguson, 1981; CliftonHadley et al. 1986; Bettge et al. 2008).

Clinical disease outbreaks occur seasonally during the summer months, and can cause high mortalities in salmonid populations (Ferguson and Ball, 1979; Ferguson, 1981; Clifton-Hadley et al. 1986). The seasonality of PKD outbreaks appears to be related to water temperature, as clinical disease signs and mortalities increase at water temperatures above

\footnotetext{
* Corresponding author: Tel: +413163124 65. Fax:
} +41316312611.E-mail: thomas.wahli@itpa.unibe.ch $15^{\circ} \mathrm{C}$ (Ferguson and Ball, 1979; Ferguson, 1981; Clifton-Hadley et al. 1986; Hedrick et al. 1993). The factors causing enhanced disease manifestation and mortalities of the fish host at elevated water temperatures are not understood to date. Increasing water temperature is associated with an increasing release of infective spores from bryozoans (Tops et al. 2006), which may result in enhanced infection pressure on the fish. At the same time, higher water temperature may promote parasite proliferation in the fish host as suggested by Bettge et al. (2009) and Gay et al. (2001), and the resulting increase of infection intensity could then lead to the temperaturerelated elevation of mortality. Another aspect is that the fish immune system is modulated by water temperature (Le Morvan et al. 1997; Köllner and Kotterba, 2002). PKD is known to invoke an immune response to parasites. The nature and intensity of this response might be temperature dependent.

The present study investigates for rainbow trout, Oncorhynchus mykiss, the relation between water temperature, the intensity of parasite infection of the fish kidneys, and fish mortality. Methodologically, we assessed the intensity of kidney infection with parasites by quantifying the concentration of parasite DNA. To this end, we developed a real-time PCR for the $18 \mathrm{~S}$ rDNA gene of $T$. bryosalmonae. Experimentally, we assessed the relation between water temperature, parasite intensity and fish 
Table 1. Time and sampling schedule of exposed fish in infection Exp. I

(At day 0 a sample was taken before exposing the fish to river water. From days 0 to 14 the fish were exposed to river water to allow T. bryosalmonae infection, before they were transferred to the laboratory, where they were held at $16{ }^{\circ} \mathrm{C}$ for the next 14 days. At day 28 the fish were divided into groups and held at different water temperatures $\left(14{ }^{\circ} \mathrm{C}, 16^{\circ} \mathrm{C}\right.$ or $\left.19^{\circ} \mathrm{C}\right)$. The days indicate the sample points. p.e. $=$ post-exposure. $\mathrm{IHC}=$ immunohistochemistry. $)$

\begin{tabular}{lllll}
\hline \hline $\begin{array}{l}\text { Day } \\
\text { p.e. }\end{array}$ & $\begin{array}{l}\text { Temperature } \\
\left({ }^{\circ} \text { C) }\right.\end{array}$ & $\begin{array}{l}\text { Total fish } \\
\text { sampled }\end{array}$ & $\begin{array}{l}\text { Fish sampled } \\
\text { for real-time } \\
\text { PCR }\end{array}$ & $\begin{array}{l}\text { Fish sampled } \\
\text { for IHC }\end{array}$ \\
\hline 0 & $<12$ & 5 & 5 & 0 \\
14 & $12-16$ & 12 & 12 & 5 \\
28 & 16 & 20 & 17 & 4 \\
35 & 14 & 10 & 8 & 5 \\
35 & 16 & 10 & 10 & 3 \\
35 & 19 & 20 & 8 & 2 \\
42 & 14 & 10 & 8 & 4 \\
42 & 16 & 8 & 6 & 10 \\
42 & 19 & 19 & 13 & 4 \\
49 & 14 & 9 & 6 & 4 \\
49 & 16 & 8 & 10 & 4 \\
49 & 19 & 16 & & \\
\hline \hline
\end{tabular}

mortality through a combination of different incubation and temperature regimes. The fish were infected with $T$. bryosalmonae in water from a river carrying a PKD-positive salmonid population. Afterwards, the trout were transferred into the laboratory to exclude a further infection by spores from the river water. In the laboratory, the fish were then exposed to different temperature regimes in order to evaluate how these conditions influence parasite proliferation in the kidney and how the latter relates to mortality.

\section{MATERIALS AND METHODS}

\section{Experimental design}

In a first experiment, started in July 2005, 425 young-of-the year rainbow trout originating from a commercial trout farm without any PKD history were used (infection Exp. I, Table 1). Before exposure, the fish were held in the trout farm at temperatures below $12{ }^{\circ} \mathrm{C}$. From this batch, 5 randomly sampled fish were tested negative for the presence of $T$. bryosalmonae by real-time PCR. The remaining 420 trout were exposed for 14 days to river water, where they experienced a temperature range of 12 to $16{ }^{\circ} \mathrm{C}$. In this river, trout infected with T. bryosalmonae had regularly been detected during the last years. After the 14-day exposure in the field, the fish had reached a PKD prevalence of $100 \%$ tested by real-time PCR in a sample of 12 fish. Then the fish were transported into the facilities of the Centre for Fish and Wildlife Health (FIWI), where the trout were kept in tanks supplied with tap water. Sixty non-exposed fish (control fish) were cohabitated with the river water-exposed trout in the laboratory in the same tanks. For identification, the adipose fin was cut from these control animals. Cohabitation of infected and non-infected fish is possible since transmission of the parasite from fish to fish does not occur (Ferguson and Ball, 1979). As the kinetics of parasite proliferation in the fish host was unknown, we exposed the fish in the first experiment to a uniform temperature $\left(16{ }^{\circ} \mathrm{C}\right.$, corresponding to the river water temperature) during the first 2 weeks of laboratory rearing until the appearance of initial disease signs. Then the fish should have been transferred to 2 temperature levels, $14{ }^{\circ} \mathrm{C}$ and $19{ }^{\circ} \mathrm{C}$, respectively, in 2 replicates per temperature. However, due to a technical failure of the cooling system, only 1 of the 2 $14{ }^{\circ} \mathrm{C}$-replicates could be maintained at the foreseen temperature, while in the other group temperature was $16{ }^{\circ} \mathrm{C}$, resulting in 3 different temperature levels, i.e. 14,16 and $19^{\circ} \mathrm{C}, 2$ of them with 1 replicate only $\left(14\right.$ and $\left.16{ }^{\circ} \mathrm{C}\right)$ which limited the number of fish available for sampling. The temperature transfer was carried out over 1 day. Sampling of fish was done at day 0 , at the end of the 14-day exposure period in the river water, after the 14 days acclimation period in the laboratory, and, after temperature transfer, at days 35, 42 and 49 post-exposure (p.e.) at each temperature (Table 1). Mortality was recorded during the experiment and expressed as cumulative mortality.

In infection Exp. II (Table 2), started in September 2006, 425 young-of-the year rainbow trout were used, which originated from the same commercial trout farm as the trout for Exp. I. Before exposure, 5 randomly sampled fish were tested for the presence of $T$. bryosalmonae by real-time PCR 
Table 2. Time and sampling schedule of exposed fish in infection Exp. II

(At day 0 a sample was taken before exposing the fish to river water. From days 0 to 5 the fish were exposed to river water to allow $T$. bryosalmonae infection. Immediately after transfer to the laboratory, the fish were divided into 2 groups and held at different water temperatures $\left(12{ }^{\circ} \mathrm{C}\right.$ or $\left.18^{\circ} \mathrm{C}\right)$. The days indicate the sample points. p.e. $=$ post-exposure. $\mathrm{IHC}=$ immunohistochemistry.)

\begin{tabular}{lcccc}
\hline \hline $\begin{array}{l}\text { Day } \\
\text { p.e. }\end{array}$ & $\begin{array}{l}\text { Temperature } \\
\left({ }^{\circ} \text { C) }\right.\end{array}$ & $\begin{array}{l}\text { Total fish } \\
\text { sampled }\end{array}$ & $\begin{array}{l}\text { Fish sampled } \\
\text { for real-time } \\
\text { PCR }\end{array}$ & $\begin{array}{l}\text { Fish sampled } \\
\text { for IHC }\end{array}$ \\
\hline 0 & $<12$ & 5 & 5 & 0 \\
5 & $12-16$ & 20 & 15 & 10 \\
12 & 12 & 10 & 10 & 5 \\
12 & 18 & 10 & 9 & 5 \\
19 & 12 & 10 & 9 & 5 \\
19 & 18 & 10 & 10 & 5 \\
26 & 12 & 10 & 10 & 6 \\
26 & 18 & 10 & 10 & 5 \\
33 & 12 & 10 & 10 & 4 \\
33 & 18 & 10 & 9 & 5 \\
47 & 12 & 10 & 10 & 5 \\
47 & 18 & 10 & 10 & \\
\hline \hline
\end{tabular}

and found to be negative. The remaining 420 trout were exposed in a tank fed with river water at $12-16{ }^{\circ} \mathrm{C}$ for 5 days as described above. At the end of the 5-day exposure period in the river water, 15 fish were tested for T. bryosalmonae DNA by means of real-time PCR. All 15 fish were found to be positive. The remaining fish were transferred to the laboratory. In this second experiment, we applied different temperature regimes immediately after transfer into the laboratory in order to examine how this influences parasite proliferation and the maximum levels of parasite DNA. The trout were divided into 2 groups with 200 fish each and kept in tanks supplied with tap water. One group was kept at a water temperature of $18{ }^{\circ} \mathrm{C}$, while the second group was kept at $12{ }^{\circ} \mathrm{C}$. The temperature transfer was carried out over 1 day. After temperature transfer, samples were taken at days $12,19,26,33$ and 47 p.e. at each temperature (Table 2). Over the whole experimental period, mortalities were checked daily and expressed as cumulative mortality.

In both experiments fish were kept in 1001 tanks with a flow through system and constant aeration. Oxygen concentration in all tanks was $\geqslant 8 \mathrm{mg}^{-1}$ during the experimental period. Fish were fed commercial trout pellets (HOKOVIT, Bützberg, Switzerland) with a daily food ratio equal to $1-2 \%$ of body weight. Animals which died in between the samplings were subjected to necropsy and to a parasitological and bacteriological examination.

For all sampled fish, fresh mounts of skin and gill samples and the intestinal content were examined microscopically for the presence of parasites. Until day 19, the river water-exposed fish in Exp. II showed an infection with Ichthyophthirius multifiliis. The fish were treated with a $3 \% \mathrm{NaCl}$ bath, eventually leading to a total disappearance of the parasites. During this period no mortality attributable to I. multifiliis was detected.

Sampled fish were euthanized in buffered 3aminobenzoic acid ethyl ester (MS 222 ${ }^{\circledR}$, Argent Chemical Laboratories, Redmont, USA), dissected and assessed for external and internal signs of the clinical stage of PKD, including darkening, exophthalmia, anaemic gills, kidney swelling or ascites. Since the intensity of kidney swelling goes more or less in parallel with the progression of the disease, each dissected fish was assigned a semiquantitative 'kidney-swelling index' to estimate the disease status. The swelling index ranged from 0 to 3 , and was based on the index described by Clifton-Hadley et al. (1987) as follows: Grade 1 : kidney enlarged along its length, especially at the posterior end; Grade 2: kidney very enlarged with marked corrugation of the kidney surface; Grade 3: kidney, mottled grey, further swollen due to oedema, with clear fluid running from cut surfaces.

After the macroscopical assessment, kidneys were carefully removed, weighed, and cut along the longitudinal axis into 2 equal parts. One half was frozen in liquid nitrogen for real-time PCR analyses, and the other half was fixed in $10 \%$ buffered formalin for immunohistochemistry.

\section{DNA preparation}

Total DNA of rainbow trout kidneys was extracted from approximately $50-100 \mathrm{mg}$ of frozen kidney tissue of each fish with DNAzol (Lucerna, Luzern, Switzerland) according to the manufacturer's protocol. The extracted DNA was resuspended in $8 \mathrm{~mm}$ $\mathrm{NaOH}$ and stored at $4{ }^{\circ} \mathrm{C}$. The yield was determined 
by spectrophotometry using the NanoDrop photometer (NanoDrop Technologies, Inc., Wilmington, USA).

\section{Cloning of $18 S$ rDNA gene of T. bryosalmonae}

A 435 bp nucleotide sequence of the 18S rDNA gene of $T$. bryosalmonae was chosen from GenBank (Accession no. AF190669; Canning et al. 1999) and amplified with the use of the primers PKX5f and PKX6r designed by Kent et al. (1998). The PCR product was then cloned into the $\mathrm{pCR}^{\circledR}-\mathrm{TOPO}^{\mathrm{R}}$ vector using the TOPO TA Cloning ${ }^{\circledR}$ Kit (Invitrogen, Basel, Switzerland) following the manufacturer's protocol. The vector plasmid DNA was purified with the QIAprep Miniprep ${ }^{\circledR}$ kit (Qiagen, Basel, Switzerland) and resuspended in $8 \mathrm{~mm}$ $\mathrm{NaOH}$. The yield was determined by spectrophotometry using the NanoDrop photometer. The plasmid DNA was amplified and sequenced in order to verify the sequence of the insert.

\section{Real-time PCR primer and probe design}

A primer and probe combination for the $18 \mathrm{~S}$ rDNA was designed using the Primer express software (PE Biosystems, Foster City, CA, USA). Then a BLAST search to identify homology of the primer and probe combination to other genetic sequences was performed to exclude non-specific amplification. Primers and probe were constructed by Microsynth (Balgach, Switzerland). Forward and reverse primers were designed to amplify a 73 base-pair region of the selected $18 \mathrm{~S}$ rDNA sequence (primer PKDtaqf1 : 5'-GCGAGATTTGTTGCATTTAAAAAG-3' and primer PKDtaqr1: 5'-GCACATGCAGTGTCCAATCG-3'). The length of the real-time PCR products was kept purposely short to enable high amplification efficiencies. The internal probe was labelled at the 5 'end with the reporter dye 6 -carboxyfluorescein (FAM) and at the 3 'end with the quencher dye 6-carboxytetramethyl-rhodamine (TAMRA) (probePKD: 5'-CAAAATTGTGGAACCGTCCGACTACGA-3'). To test the suitability of the primer combination, a conventional PCR according to Kent et al. (1998) was performed with the new primers and the products were checked on an agarose gel for amplification and molecular weight. The quantitative real-time PCR amplification was performed as follows. The reaction volume of $25 \mu \mathrm{l}$ containing $1 \times$ TaqMan universal Master Mix (Applied Biosystems, Rotkreuz, Switzerland), $300 \mathrm{~nm}$ forward primer, $300 \mathrm{nM}$ reverse primer, $200 \mathrm{nM}$ fluorescent labelled probe, and $2 \mu \mathrm{g}$ extracted DNA from the trout kidney as template. Amplification was done in an $\mathrm{Mx} 4000{ }^{\circledR}$ Multiplex Quantitative PCR System (Stratagene, La Jolla, CA, USA). The amplification conditions consisted of initial denaturation at $95{ }^{\circ} \mathrm{C}$ for $10 \mathrm{~min}$, followed by 45 cycles of
$15 \mathrm{~s}$ at $95{ }^{\circ} \mathrm{C}$ and $1 \mathrm{~min}$ at $60^{\circ} \mathrm{C}$. All samples were analysed in duplicate.

\section{Preparation of standard curves and data analysis}

The cloned region of the $18 \mathrm{~S}$ rDNA gene of $T$. bryosalmonae was used for the generation of standard curves. To calculate the copy numbers of the standard curve, nucleotide length and plasmid concentration were used (Yin et al. 2001). A stock solution of $20 \mathrm{pg}$ plasmid DNA was calculated to be equivalent to $3 \cdot 14 \times 10^{5}$ copies of the $18 \mathrm{~S}$ rDNA sequence of the parasite. From this stock solution, a 10 -fold serial dilution in buffer $(8 \mathrm{~mm} \mathrm{NaOH})$ was prepared, subjected to real-time PCR and the obtained threshold cycle values $\left(\mathrm{C}_{t}\right)$ were plotted against the quantity of the plasmid DNA. The assay conditions to measure the samples of the standard curve were identical to those used for the fish samples. The regression equation obtained for the standard curve of the $18 \mathrm{~S}$ rDNA of $T$. bryosalmonae was then used to convert the measured $C_{t}$ value of an unknown sample into copy numbers of parasite DNA. A reference sample with known copy numbers of plasmid DNA was measured together with the samples to calibrate each run. The PCR product of the reference sample was sequenced to verify the specificity of the real-time PCR. Additionally all $\mathrm{C}_{\mathrm{t}}$ values of 32 and more were excluded from the calculations, because sequencing of PCR products resulting from amplification cycles of 32 and more showed, that under these conditions unspecific sequences were amplified.

Target DNA was normalized against total DNA extracted from the kidney tissue. For comparison, results were normalized against fish weight. To this end, the copy numbers of parasite DNA were converted to copy numbers per fish using the individual fish kidney weights.

\section{Immunohistochemical examination of the kidneys}

Immunohistochemical staining of parasites in the kidney was conducted to compare the number of immunohistochemically stained parasites in the kidney with renal copy numbers of parasite DNA determined by real-time PCR. To this end, we performed immunohistochemical staining of T. bryosalmonae on kidney sections with a monoclonal anti-T. bryosalmonae antibody (AquaMAb-P01, Aquatic Diagnostics Ltd, Stirling, UK) and counted the number of stained parasites on the sections. The immunohistochemical staining was performed according to the protocol of Adams et al. (1992) with minor modifications. Briefly, unstained sections were incubated overnight using an antibody dilution of $1 / 100$. Unspecific background staining was blocked with goat serum. A biotin-streptavidin-horseradish peroxidase staining kit (Kit Dako LSAB 2 System 
HRP Code Nr. K0675; DakoCytomation, Zug, Switzerland) followed by AEC (Amino-EthylCarbazole) staining (DAKO AEC K3464) was used to visualize antibody-antigen complexes. Counterstaining of these sections was not performed. Kidney tissue of a fish known to be PKD-positive was used as a positive control. Slides incubated without the first antibody were used as negative controls. The immunohistochemical slides were evaluated with a light microscope at a magnification of $400 \times$ (high-power field). The number of parasites per high-power field was counted in 3 randomly selected fields per slide. The average number of parasites per fish was compared to the quantity of parasite DNA copies determined by means of real-time PCR for the same individual. This comparison was possible, because the kidneys used for PCR and immunohistochemistry originated from the same fish.

\section{Statistical analysis}

The cumulative mortality of the different groups was compared and tested for significant differences using the chi-square-test and a $P \leqslant 0 \cdot 05$ significance level. The amounts of parasite DNA as determined by realtime PCR at different time-points were tested for normal distribution with the Skewness, Kurtosis and Omnibus Normality tests, and then compared and tested for significant differences using the MannWhitney U or Wilcoxon Rank-Sum test with a $P \leqslant 0.05$ significance level because the values were not normally distributed. The kidney-swelling index at different time-points was compared between the different temperatures and tested for significant differences using the Mann-Whitney U or Wilcoxon Rank-Sum test and $P \leqslant 0 \cdot 05$ significance level as values were not normally distributed. For all statistical tests, NCSS 2001 (Hintze, 2006) was used.

\section{RESULTS}

\section{Standard curve/dynamic range of the real-time PCR}

The standard curve prepared by a 10 -fold serial dilution of the cloned $18 \mathrm{~S}$ rDNA region was linear over 5 logs of plasmid dilution, when mean $\mathrm{C}_{\mathrm{t}}$ values obtained for the standard dilutions were plotted against the calculated quantity of the plasmid. The average slope of the regression equations from 4 independent repetitions of the serial dilution of the DNA standard was $-3 \cdot 4477 \pm 0 \cdot 09$ with a correlation coefficient of $r^{2}=0.9996$ (Fig. 1). The PCR efficiency for a tissue dilution curve obtained by dilution of DNA from the kidney of a fish infected with $T$. bryosalmonae resulted in a regression of $-3 \cdot 561$.

To evaluate whether changes of parasite DNA copy numbers as determined by real-time PCR correlate with changes in parasite numbers as seen on

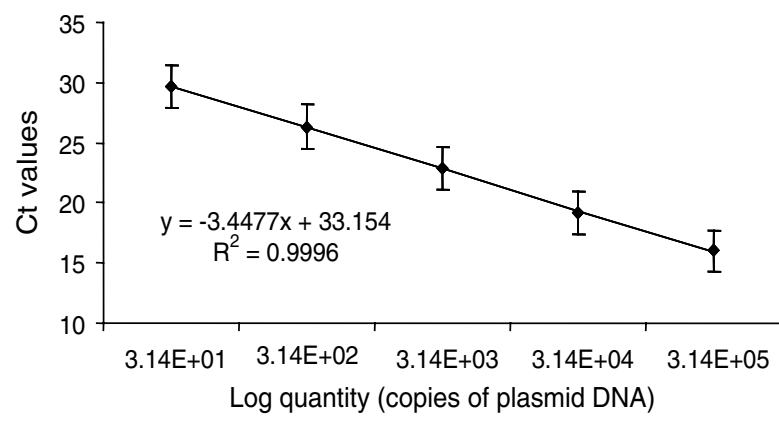

Fig. 1. Real-time PCR standard curve plotted as mean $\mathrm{C}_{t}$ values versus known quantities of a plasmid containing the $435 \mathrm{bp}$ nucleotide sequence of the $18 \mathrm{~S}$ rDNA region of Tetracapsula bryosalmonae diluted into buffer. The PCR efficiency was $94.9 \%$. Standard deviations show the inter-assay variability $(n=4)$.

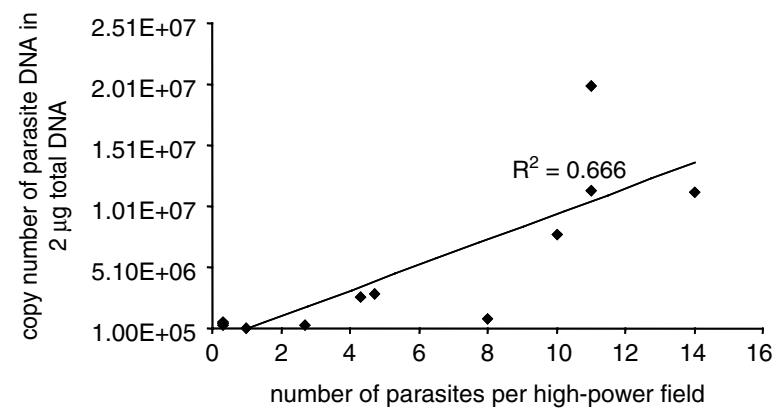

Fig. 2. Comparison between quantitative real-time PCR and immunohistochemistry on kidneys with different degrees of infection. No correlation was seen for fish showing no immunodetectable parasites per high-power field and for fish with $>20$ parasites per high-power field. These fish were excluded from the regression curve.

immunohistochemical sections, the PCR samples were compared to the corresponding slides prepared from the same individuals as used for the quantitative real-time PCR. This comparison was performed exclusively on fish which had been exposed to river water and therefore were expected to be infected. A linear correlation was observed for fish showing $>0-20$ parasites per high-power field (magnification $400 \times$ ) with a correlation coefficient of $r^{2}=0 \cdot 666$ (Fig. 2 ). When fish with immunohistochemically-intense infections (parasite numbers per high-power field of $>20$ ) were included in the dataset, no correlation between PCR results and parasite counts was found $\left(r^{2}=0.0172\right.$; data not shown). Also no correlation $\left(r^{2}=0.0071\right.$; data not shown $)$ was obtained when fish with no immunohistochemical staining of parasites were included in the dataset. In this case, the individuals yielded a positive PCR signal but showed no immunoreactivity for $T$. bryosalmonae.

\section{Infection Experiment I}

Infection phase. Naive rainbow trout were exposed for 14 days to river water, in which the resident 


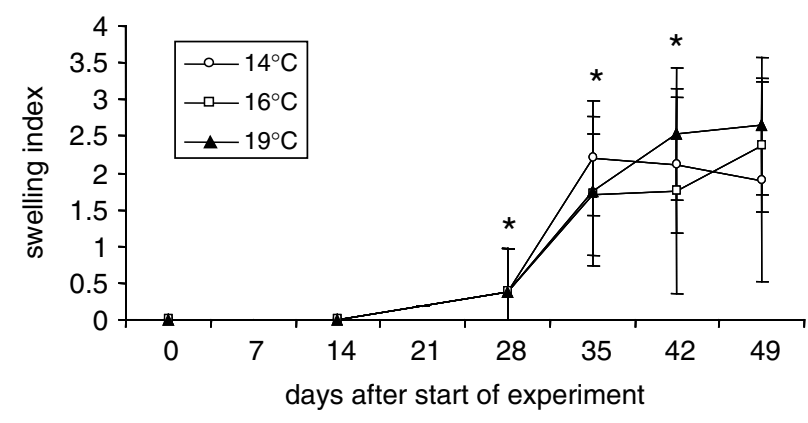

Fig. 3. Infection Exp. I. - swelling index of kidneys in fish subjected to different temperature treatments. The experiment covers the period from initial infection to the clinical disease phase. Before subjecting fish to different temperatures, $n=5,12$ and 20 at days 0,14 and 28 ; $n=9-10$ at $14{ }^{\circ} \mathrm{C}, n=8-10$ at $16^{\circ} \mathrm{C}$, and $n=16-20$ at $19{ }^{\circ} \mathrm{C}$ for sample points after subjecting fish to different temperatures. The asterisks indicate a significant increase of the kidney-swelling index to the previous sample $(P \leqslant 0 \cdot 05$.$) in all groups (except at day 42$, which refers to the $19^{\circ} \mathrm{C}$-group).

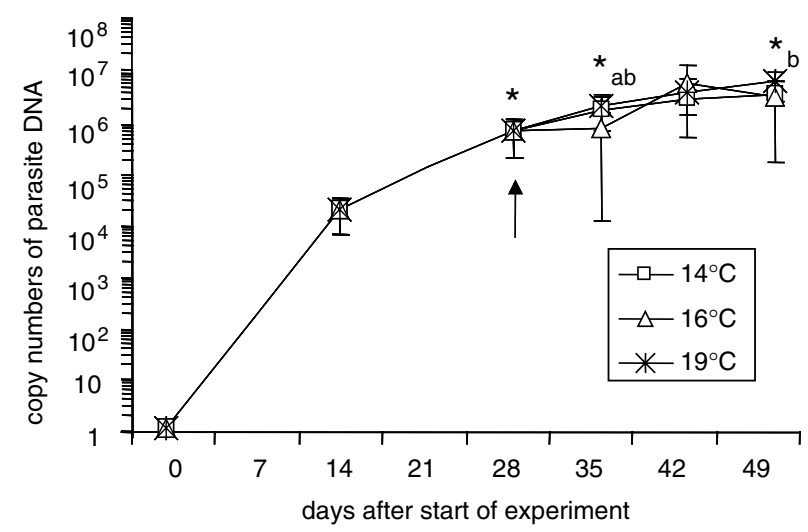

Fig. 4. Infection Exp. I - copy numbers of parasite DNA per $2 \mu \mathrm{g}$ of total DNA. The arrow indicates the time-point, when fish were subdivided into 3 groups. The asterisks indicate significant differences to the previous sample $(P \leqslant 0 \cdot 05),. \mathrm{a}=14{ }^{\circ} \mathrm{C}, \mathrm{b}=16{ }^{\circ} \mathrm{C}$.

brown trout population was regularly found to be positive for $T$. bryosalmonae indicating that the parasite was present endemically. None of 12 fish analysed after the exposure period of 14 days showed any macroscopical signs of a $T$. bryosalmonae infection (Fig. 3). In contrast, by means of real-time PCR all 12 fish proved to be positive for T. bryosalmonae (Fig. 4).

Acclimation phase. Within the 14 days of acclimation at $16{ }^{\circ} \mathrm{C}$, which followed the river exposure period (days 14 to 28 p.e.) the kidney swelling increased only slightly (Fig. 3), while a significant $(P \leqslant 0 \cdot 05)$ increase in copy numbers of parasite DNA from $2 \cdot 7 \times 10^{4}$ to $1 \cdot 1 \times 10^{6}$ was evident (Fig. 4 ).

Exposure phase to different temperatures. After 14 days of river exposure and subsequent 14 days of

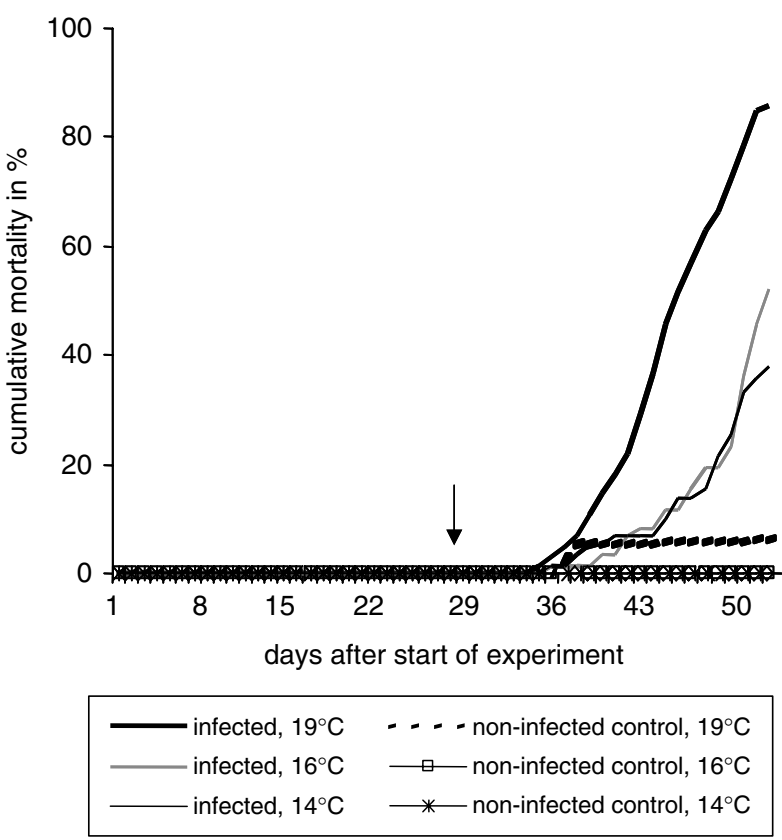

Fig. 5. Infection Exp. I - cumulative mortality of Tetracapsula bryosalmonae-infected fish kept at different temperatures and uninfected control fish, cohabitated with the infected fish. The arrow indicates the time-point when fish were subdivided into 3 temperature groups.

laboratory adaptation phase, groups of fish were transferred to different temperatures. In animals kept at $14{ }^{\circ} \mathrm{C}$ and at $16{ }^{\circ} \mathrm{C}$, the kidney-swelling index increased significantly until day 35 , while in animals kept at $19^{\circ} \mathrm{C}$ a significant increase was recorded until day 42 (Fig. 3). Regarding development of copy numbers of parasite DNA, in fish kept at $14{ }^{\circ} \mathrm{C}$ a significant increase was found between days 28 and 35 , thereafter no further significant changes occurred (Fig. 4). At $16{ }^{\circ} \mathrm{C}$, parasite DNA concentrations showed a slight increase but the differences were not significant when compared to the values measured at day 28 (Fig. 4). At $19{ }^{\circ} \mathrm{C}$, parasite DNA concentrations increased significantly until the end of the experiment, although the rate of DNA augmentation was not as pronounced as that seen between days 14 and 28 (Fig. 4). Comparisons of parasite DNA levels between all 3 temperature groups revealed no significant differences between the treatments at any time-point. None of the control fish in any of the temperature regimes showed positive results for parasite DNA.

Mortality. Mortality first occurred at day 31, i.e. 3 days after separation of fish into different temperature groups. Cumulative mortalities varied significantly with water temperature (Fig. 5). Infected fish held at $19^{\circ} \mathrm{C}$ experienced a cumulative mortality over the experiment of $85.0 \%$ (day 49 p.e.). At $16{ }^{\circ} \mathrm{C}$, cumulative mortality reached $45.5 \%$ and at $14{ }^{\circ} \mathrm{C}$ cumulative mortality was $35.7 \%$. In the control groups, a total of $5.9 \%$ of fish died at $19{ }^{\circ} \mathrm{C}$, 


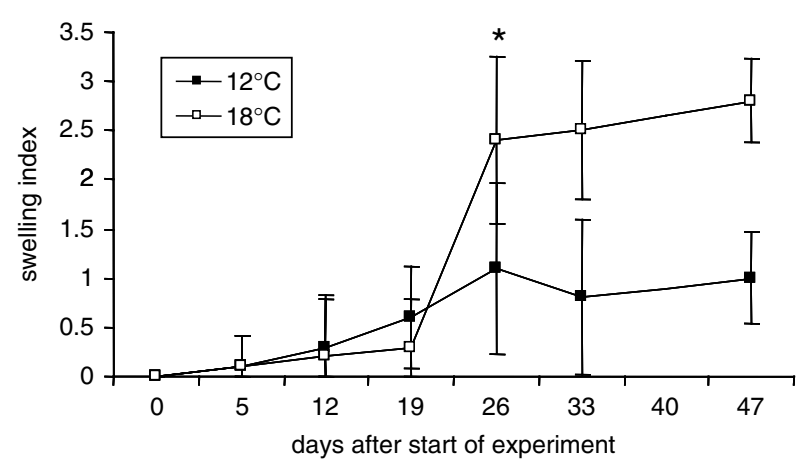

Fig. 6. Infection Exp. II - swelling index of kidneys in fish subjected to different temperature treatments. The experiment covers the period from initial infection to the clinical disease phase. Before subjecting fish to different temperatures, $n=5$, at day 0 and $n=20$ at day 5; $n=10$ per temperature group and sampling point from day 12 onwards. The asterisk indicates a significant increase of the kidney swelling index to the previous sample $(P \leqslant 0 \cdot 05$. $)$ in the $18{ }^{\circ} \mathrm{C}$ group.

whereas no mortalities occurred at $16{ }^{\circ} \mathrm{C}$ and $14{ }^{\circ} \mathrm{C}$, respectively.

\section{Infection Experiment II}

Considering the short period in the river water needed to achieve $100 \%$ prevalence of a $T$. bryosalmonae infection and the non-significant differences in DNA copy numbers between the different temperature regimes in Exp. I, 3 factors were changed in the second experiment. The exposure time to river water was reduced to 5 days, the adaptation period in the laboratory was omitted and a more pronounced temperature difference was chosen, namely $12{ }^{\circ} \mathrm{C}$ and $18^{\circ} \mathrm{C}$.

Infection phase. After 5 days of exposure to river water, macroscopic signs of infection characterized by slightly enlarged kidneys were observed in 2 out of 20 fish. Real-time PCR confirmed that all 15 fish tested were infected with T. bryosalmonae (Fig. 7). Copy numbers were similar to those observed in Exp. I at the end of the 14-day exposure period $\left(10^{4}-10^{5}\right.$ copies per $2 \mu \mathrm{g}$ total kidney DNA).

Exposure phase to different temperatures. After transfer of fish to the different temperatures in the laboratory, the kidney-swelling index increased slowly until day 19 p.e., independent of the temperature (Fig. 6). Between days 19 and 26, fish reared at $12{ }^{\circ} \mathrm{C}$ showed still a moderate, non-significant elevation of kidney swelling, while fish reared at $18^{\circ} \mathrm{C}$ showed a significant increase in kidney swelling (Fig. 6). From day 26 p.e. onwards, no further increase was recorded, either at 12 or $18{ }^{\circ} \mathrm{C}$. Thus, both temperature groups showed a similar timecourse of kidney swelling, but differed in the intensity of the response.

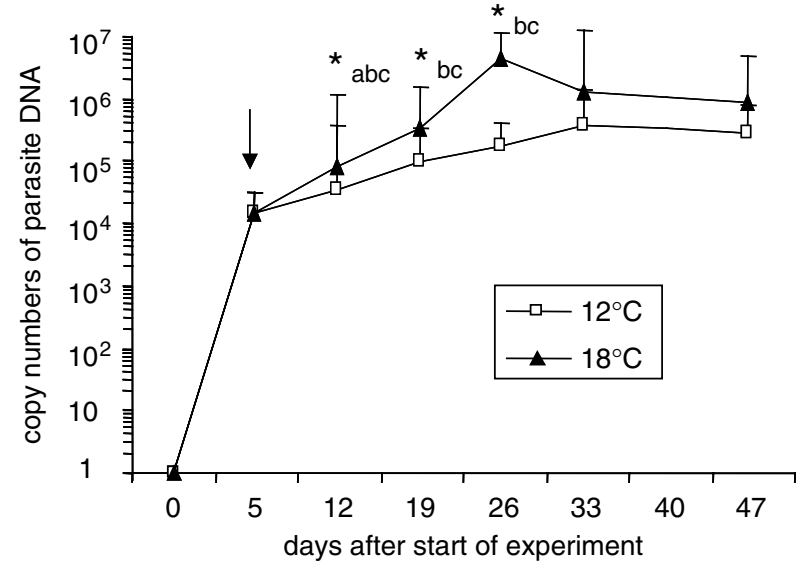

Fig. 7. Infection Exp. II - copy numbers of parasite DNA per $2 \mu \mathrm{g}$ of total DNA. The arrow indicates the time-point when fish were subdivided into 2 groups. An asterisk indicates a significant difference $(P \leqslant 0 \cdot 05$.), $\mathrm{a}=12{ }^{\circ} \mathrm{C}$ to the previous sample, $\mathrm{b}=18{ }^{\circ} \mathrm{C}$ to the previous sample, $\mathrm{c}=$ between both groups.

After transfer of the fish to the laboratory (at day 5) parasite DNA concentrations in the kidney increased in a time- and temperature-dependent manner (Fig. 7). In the $12{ }^{\circ} \mathrm{C}$-group, a significant increase of parasite DNA occurred from day 5 to day 12 p.e.. Thereafter, copy numbers continued to increase slightly, but the increase was not significant (Fig. 7). In contrast, in fish reared at $18{ }^{\circ} \mathrm{C}$, parasite DNA in the kidneys increased significantly from day 12 until day 26, when it reached a maximum (Fig. 7). Thereafter, parasite DNA levels in fish reared at the high temperature decreased slightly, but not significantly. DNA copy numbers of T. bryosalmonae were significantly $(P \leqslant 0.05)$ higher in $18^{\circ} \mathrm{C}$ fish than in $12{ }^{\circ} \mathrm{C}$ fish at days 12,19 and 26 p.e., but not at days 33 and 47 p.e.

Since the infection is characterized by a higher level of kidney swelling in the $18{ }^{\circ} \mathrm{C}$ group than in the $12{ }^{\circ} \mathrm{C}$ group (Fig. 6), we examined whether the observed differences of parasite DNA contents between the temperature groups are related to the differences of kidney size. To this end, copy numbers of parasite DNA were normalized against a unit fish instead of kidney DNA concentration, i.e. we converted $\mu \mathrm{g} 18 \mathrm{~S} \mathrm{rDNA} / 2 \mu \mathrm{g}$ total DNA to $18 \mathrm{~S} \mathrm{rDNA} /$ fish. However, this conversion did not result in a different pattern of parasite DNA development in the infected fish (data not shown).

Mortalities of PKD-infected rainbow trout at rearing temperatures of $12^{\circ} \mathrm{C}$ and $18^{\circ} \mathrm{C}$. Cumulative mortalities varied significantly with water temperature (Fig. 8). While $77 \cdot 1 \%$ of the infected fish died at $18{ }^{\circ} \mathrm{C}$, cumulative mortality was only $5 \cdot 6 \%$ in the $12{ }^{\circ} \mathrm{C}$ treatment. 


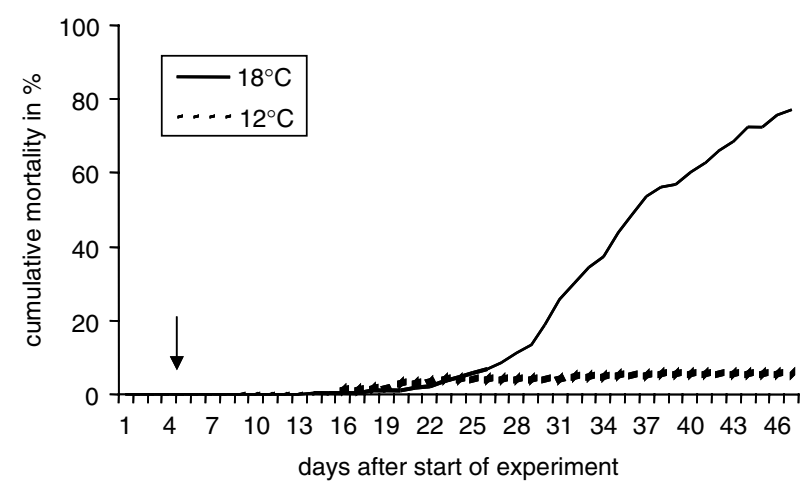

Fig. 8. Infection Exp. II - cumulative mortality of Tetrascapsula bryosalmonae-infected fish kept at different temperatures. The arrow indicates the time-point when fish were subdivided into 2 groups.

DISCUSSION

Quantification of T. bryosalmonae DNA by real-time $P C R$

We established a real-time PCR to quantify the parasite load of T. bryosalmonae in kidneys of trout using an $18 \mathrm{~S}$ rDNA sequence of the parasite. Using variable regions of the conserved $18 \mathrm{~S}$ rDNA has shown to be suitable for species identification and has therefore been widely used for the detection and identification of different myxozoans e.g. Ceratomyxa shasta (Palenzuela et al. 1999; Hallett and Bartholomew, 2006), Myxobolus cerebralis (Baldwin and Myklebust, 2002) and also T. bryosalmonae (Saulnier and De Kinkelin, 1997; Kent et al. 1998; Morris et al. 2002; Tops et al. 2005). To establish the real-time PCR we cloned a PCR product of the PCR by Kent et al. (1998) into a vector and sequenced the cloned region to verify the specificity for T. bryosalmonae. Forward and reverse primers for the real-time PCR were designed to amplify a 73 base-pair region in the selected $18 \mathrm{~S}$ rDNA sequence. Alignment using BLAST search (www.blast.ncbi. nlm.nih.gov) was performed to identify homology of the primer and probe combination to other genetic sequences to exclude non-specific amplification. No corresponding sequence was found. Specificity was also underlined by the result that none of the uninfected control fish showed a positive result.

The advantage of amplification of a multicopy gene such as the $18 \mathrm{~S}$ rDNA of $T$. bryosalmonae analysed in the present study is that it should provide high sensitivity (Hallett and Bartholomew, 2006). However, a prerequisite to using a multicopy gene for quantification of parasite numbers is the implicit assumption that the same number of copies of the gene per nucleus is present in all parasites. To estimate whether the real-time PCR indeed reflects changes in parasite numbers - instead of changes in $18 \mathrm{~S}$ rDNA-copy-numbers per parasite-, we compared the PCR results with the number of immunohistochemically detectable parasites in kidney sections of the same fish. In general, a good correlation was found, supporting the reliability of the PCR quantification method. Exceptions existed for fish with very strong or very low (in terms of DNA concentrations) infection: in both cases, PCR and immunohistochemcial results showed a poor correlation. In histological sections of heavily infected fish, parasites were often found clustering together while areas adjacent to these clusters appeared more or less parasite-free. This results in a rather imprecise estimate of parasite numbers per section when evaluated by immunohistochemistry. Similarly, in fish with very low infection levels and few parasites present in the kidney, histological examination may miss the unevenly distributed parasites. In contrast, PCR methodology, which relies on tissue extracts, is less sensitive to heterogenous micro-spatial distribution of the parasites within the kidney, and therefore is likely to provide a more accurate estimate of parasite intensity than immunohistochemistry in kidneys with very high or very low parasite loads.

\section{Infection phase in the river system}

Trout exposed to river water known to be endemic for PKD showed an infection prevalence of $100 \%$ after 14 days. This high prevalence of parasitepositive fish after 14 days in the first experiment caused us to shorten the river exposure period in Exp. II. In the latter experiment, $100 \%$ prevalence was achieved within the 5 -day exposure period. This finding suggests that infection of fish by T. bryosalmonae under natural conditions takes place rather quickly, which has also been shown by Longshaw et al. (2002). Interestingly, copy numbers of parasite DNA at termination of the river exposure were comparable in the 2 experiments $\left(10^{4}-10^{5}\right.$ copies per $2 \mu \mathrm{g}$ total kidney DNA), although the length of exposure was different in the 2 experiments. This result may be explained by a higher infection pressure in the second year of exposure, or it may indicate that the parasite level in the fish host depends less on the accumulation of spores from the environment and more on the parasite proliferation in the fish host.

How do renal concentrations of parasite DNA change with time and water temperature after transfer of fish into the laboratory?

Several publications addressed the question of temperature influence on the proliferation of parasites in fish hosts. Growth and development of other parasites in fish have been shown to be directly correlated to water temperature over a range of $9-25{ }^{\circ} \mathrm{C}$, e.g. for Ichthyophthirius multifiliis (Noe and Dickerson, 1995). Also monogenean parasites of fish (Tubbs et al. 2005; Lackenby et al. 2007) or parasitic 
arthropods like sea lice (Costello, 2006) develop faster at higher temperatures. With respect to the proliferation of T. bryosalmonae in the fish host, Kent and Hedrick (1986), Hedrick et al. (1993) and Bettge et al. (2009) observed by means of light microscopy and immunohistochemistry that the number of parasites visible in the tissue sections increases during the course of infection. To date, no studies have been published which quantified parasite proliferation in the fish host in relation to the water temperature. However, increasing water temperature has been shown to increase the proliferation of $T$. bryosalmonae in the invertebrate host, the bryozoans (Tops et al. 2006).

In the 2 experiments of this study, we observed an initial phase of parasite proliferation that lasted for 20 to 30 days post-infection, independent of the temperature that fish were exposed to. After that phase, parasite augmentation slowed down and tended to achieve a satiation plateau or even showed a slight decrease $\left(18^{\circ} \mathrm{C}\right.$ treatment). Similar patterns of parasite proliferation were described for Spironucleus barkhanus (Diplomonadida: Hexamitidae) in Salmo salar (Guo and Woo, 2004). In trout suffering from PKD, the phase of the highest parasite intensity coincided with the phase of maximal kidney swelling and with the clinical disease phase.

A major aim of our study was to examine whether and how water temperature modifies the parasite proliferation in the fish kidney. The findings from the 2 experiments suggest that temperature does not so much influence the amount of parasite DNA in the fish during the clinical disease phase, but has its main influence on the kinetics of parasite proliferation. The evidence supporting this interpretation comes from the observation that in Exp. I, when the fish were maintained over an extended period at the same water temperature, the subsequent transfer to different temperatures had no significant effect on the parasite DNA copy numbers in the kidneys. In contrast, in the second experiment, where fish were exposed to different water temperatures immediately after the infection phase in the river, different slopes in the increase of parasite DNA were seen during this proliferation phase. In the $12{ }^{\circ} \mathrm{C}$ group, the proliferation phase was fairly short, with parasite DNA levels not increasing significantly anymore from day 19 p.e. onwards until the end of the experiment. In the $18{ }^{\circ} \mathrm{C}$ group, however, parasite DNA levels increased significantly over a longer period until reaching a peak at day 26 p.e., followed by a decline of parasite numbers to levels that were no longer significantly different to the $12{ }^{\circ} \mathrm{C}$ group. Thus, the low temperature was characterized by an increase in DNA levels until they reached a constant value while at the high water temperature, DNA levels peaked and then declined. The decrease of parasite DNA at the high water temperature is probably not the result of an enhanced elimination

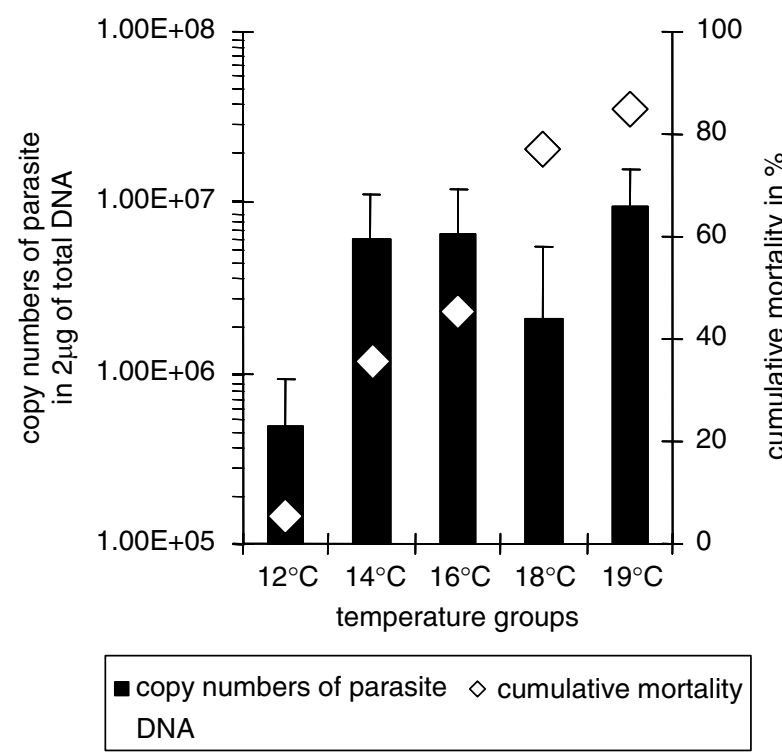

Fig. 9. Comparison of the copy numbers of parasite DNA per $2 \mu \mathrm{g}$ of total DNA with the cumulative mortality at the end of the experiment. Data are plotted for day 47 for 12 and $18{ }^{\circ} \mathrm{C}$ and day 49 for 14,16 and $19^{\circ} \mathrm{C}$.

of the parasite via urine, but appears to result from an onset of degradation of parasites (Bettge et al. 2009) in the interstitial tissue as well as resident sporogonic parasites in the tubules. This hypothesis is also supported by the high inter-individual variation in copy numbers at the last sampling point of the $18^{\circ} \mathrm{C}$ group.

\section{What is the relation between temperature and disease-associated mortality?}

The aforementioned observation on the influence of temperature on parasite proliferation and intensity leads to the question of how this relates to the temperature influence on mortality of PKD-infected fish. Our results show that PKD-induced mortality was significantly different between all temperature groups, both in Exp. I and Exp. II (Fig. 9). Our findings are well in agreement with published data showing that PKD evokes highest mortalities at temperatures of $15{ }^{\circ} \mathrm{C}$ or above (Ferguson, 1981; Clifton-Hadley et al. 1986; Hedrick et al. 1993). The pronounced effect of temperature on mortality is in contrast to the less pronounced temperature effect on parasite DNA in the fish kidney. These findings suggest that it is not the mere number of parasites in the host kidney that is the main causative factor for the PKD-induced mortality.

If temperature-related differences of mortality show no direct correlation with renal parasite loads other, probably more indirect factors, appear to be responsible. An important factor could be the intensity of kidney lesions, which are, more pronounced at $18{ }^{\circ} \mathrm{C}$ than at $12{ }^{\circ} \mathrm{C}$ (Bettge et al. 2009). 
The advanced pathological reaction of the kidney might be related to an enforced immune reaction of the fish kept at $18{ }^{\circ} \mathrm{C}$ as reported for other fish diseases as well (Le Morvan et al. 1997; Köllner and Kotterba, 2002; Nikoskelainen et al. 2004; Pérez-Casanova et al. 2008). The immune response then would lead to a proliferation of the interstitial tissue and to a regression or displacement of glomeruli and tubules. These pathological changes are likely to cause kidney dysfunction and could thereby compromise the capability of the fish for osmoregulation, and/or haematopoiesis. This might be fatal as the higher water temperatures impose increased functional demands on both osmoregulation and respiration. Osmotic water inflow into the fish is probably elevated at the higher water temperature, which challenges the damaged kidney with an increased need for water excretion. Similarly, high water temperature leads to an increased oxygen demand due to the combination of elevated metabolism and reduced ambient oxygen levels. This demand can possibly not be met due to the reduced haematopoietic capacity of the damaged kidney tissue as evidenced by the marked anaemia in the clinical phase of the PKD.

In conclusion, this study provides evidence that the parasite undergoes its main proliferation phase during the first 20 to 30 days after infection. Temperature modulates parasite proliferation particularly during this phase. At a later phase, the amount of parasite DNA in all temperature groups approached similar levels except at $12{ }^{\circ} \mathrm{C}$. The main proliferation of parasite DNA occurred before the onset of mortalities due to PKD. While the present study confirms the temperature dependency of PKD-induced mortalities, the results of this study argue against a direct relationship between parasite intensity and fish mortality. It appears that a combination of parasite induced renal dysfunction - due to a strongly enhanced host response at higher water temperatures-together with temperature related increasing demands on kidney function may ultimately cause the death of $T$. bryosalmonae-infected fish.

We thank Ursula Forster for performing the immunohistochemisty, Ursula Sattler for assisting with the realtime PCR, and the staff of the histology laboratory of the institute for preparation of the histological sections. Patricia Holm is acknowledged for helpful comments and discussion.

\section{REFERENCES}

Adams, A., Richards, R. H. and De Mateo, M. (1992). Development of monoclonal antibodies to $\mathrm{PK}$ ' $\mathrm{X}$ ', the causative agent of proliferative kidney disease. Fournal of Fish Diseases 15, 515-521.

Baldwin, T. J. and Myklebust, K. A. (2002). Validation of a single round polymerase chain reaction assay for identification of Myxobolus cerebralis myxospores.

Diseases of Aquatic Organisms 49, 185-190.

Bettge, K., Wahli, T., Segner, H. and

Schmidt-Posthaus, H. (2009). Proliferative kidney disease in rainbow trout: time and temperature-related renal pathology and parasite distribution. Diseases of Aquatic Organisms 83, 67-76.

Canning, E. U., Curry, A., Feist, S. W., Longshaw, M. and Okamura, B. (1999). Tetracapsula bryosalmonae N. SP. for PKX organism, the cause of PKD in salmonid fish. Bulletin of the European Association of Fish Pathologists 19, 203-206.

Canning, E. U., Tops, S. A., Curry, A., Wood, T. S. and Okamura, B. (2002). Ecology, development and pathogenicity of Buddenbrockia plumatellae Schröder, 1910 (Myxozoa, Malacosporea) (syn. Tetracapsulua bryozoides) and establishment of Tetracapsuloides $\mathrm{n}$. gen. for Tetracapsula bryosalmonae. Fournal of Eucaryotic Microbiology 49, 280-295.

Clifton-Hadley, R. S., Richards, R. H. and Bucke, D. (1986). Proliferative kidney disease (PKD) in rainbow trout, Salmo gairdneri: Further observations on the effects of temperature. Aquaculture 55, 165-171.

Clifton-Hadley, R. S., Bucke, D. and Richards, R. H. (1987). A study of the sequential clinical and pathological changes during proliferative kidney disease in rainbow trout, Salmo gairdneri Richardson. Fournal of Fish Diseases 10, 335-352.

Costello, M. J. (2006). Ecology of sea lice parasitic on farmed and wild fish. Trends in Parasitology 22, 475-483.

Feist, S. W., Longshaw, M., Canning, E. U. and Okamura, B. (2001). Induction of proliferative kidney disease (PKD) in rainbow trout Oncorhynchus mykiss via the bryozoan Fredericella sultana infected with Tetracapsula bryosalmonae. Diseases of Aquatic Organisms 45, 61-68.

Ferguson, H. W. and Ball, H. J. (1979). Epidemiological aspects of proliferative kidney disease in rainbow trout, Salmo gairdneri Richardson in Northern Ireland. Fournal of Fish Diseases 2, 219-225.

Ferguson, H. W. (1981). Effects of temperature on the development of proliferative kidney disease in rainbow trout, Salmo gairdneri Richardson. Fournal of Fish Diseases 4, 175-177.

Gay, M., Okamura, B. and de Kinkelin, P. (2001). Evidence that infectious stages of Tetracapsula bryosalmonae for rainbow trout Oncorhynchus mykiss are present throughout the year. Diseases of Aquatic Organisms 46, 31-40.

Guo, F. C. and Woo, P. T. K. (2004). Experimental infections of Atlantic salmon Salmo salar with Spironucleus barkhanus. Diseases of Aquatic Organisms 61, 59-66.

Hallett, S. L. and Bartholomew, J. L. (2006). Application of a real-time PCR as a way to detect and quantify the myxozoan parasite Ceratomyxa shasta in river water samples. Diseases of Aquatic Organisms 71, 109-118.

Hedrick, R. P., MacConnell, E. and de Kinkelin, P. (1993). Proliferative kidney disease of salmonid fish. Annual Review of Fish Diseases 3, 277-290.

Hintze, J. (2006). NCSS, PASS, and GESS. NCSS. Kaysville, Utah. WWW.NCSS.COM, released: 19 May, 2006. 
Kent, M. L. and Hedrick, R. P. (1986). Development of the PKX myxosporean in rainbow trout Salmo gairdneri. Diseases of Aquatic Organisms 1, 169-182.

Kent, M. L., Khattra, J., Hervio, D. M. L. and Devlin, R. H. (1998). Ribosomal DNA sequence analysis of isolates of the PKX myxosporean and their relationship to members of the genus Sphaerospora. Fournal of Aquatic Animal Health 10, 12-21.

Köllner, B. and Kotterba, G. (2002). Temperature dependent activation of leucocyte populations of rainbow trout, Oncorhynchus mykiss, after intraperitoneal immunisation with Aeromonas salmonicida. Fish and Shellfish Immunology 12, 35-48.

Lackenby, J. A., Chambers, C. B., Ernst, I. and Whittington, I. D. (2007). Effect of water temperature on reproductive development of Benedenia seriolae (Monogenea: Capsalidae) from Seriola lalandi in Australia. Diseases of Aquatic Organisms 74, 235-242.

Le Morvan, C., Troutaud, D. and Deschaux, P. (1997). Differential effects of temperature on specific and nonspecific immune defences in fish. Fournal of Experimental Biology 201, 165-168.

Longshaw, M., Le Deuff, R.-M., Harris, A. F. and Feist, S. W. (2002). Development of proliferative kidney disease in rainbow trout, Oncorhynchus mykiss (Walbaum), following short-term exposure to Tetracapsula bryosalmonae infected bryozoans. Fournal of Fish Diseases 25, 443-449.

Morris, D. C., Morris, D. J. and Adams, A. (2002). Development of improved PCR to prevent false positives and false negatives in the detection of Tetracapsula bryosalmonae, the causative agent of proliferative kidney disease. Fournal of Fish Diseases 25, 483-490.

Nikoskelainen, S., Bylund, G. and Lilius, E. (2004). Effect of environmental temperature on rainbow trout (Oncorhynchus mykiss) innate immunity. Developmental and Comparative Immunology 28, 581-592.

Noe, J. G. and Dickerson, H. W. (1995). Sustained growth of Ichthyophthirius multifiliis at low temperature in the laboratory. Fournal of Parasitology 81, 1022-1024.
Okamura, B., Anderson, C. L., Longshaw, M., Feist, S. W. and Canning, E. U. (2001). Patterns of occurrence and $18 \mathrm{~S}$ rDNA sequence variation of PKX (Tetracapsula bryosalmonae), the causative agent of salmonid proliferative kidney disease. Fournal of Parasitology 87, 379-385.

Palenzuela, O., Trobridge, G. and Bartholomew, J. L. (1999). Development of a polymerase chain reaction diagnostic assay for Ceratomyxa shasta, a myxosporean parasite of salmonid fish. Diseases of Aquatic Organisms 36, 45-51.

Pérez-Casanova, J. C., Rise, M. L., Dixon, B., Afonso, L. O. B., Hall, J. R., Johnson, S. C. and Gamperl, A. K. (2008). The immune and stress responses of Atlantic cod to long-term increases in water temperature. Fish and Shellfish Immunology 24, 600-609.

Saulnier, D. and De Kinkelin, P. (1997). Polymerase chain reaction primers for investigations on the causative agent of proliferative kidney disease of salmonids. Fournal of Fish Diseases 20, 467-470.

Tops, S., Curry, A. and Okamura, B. (2005). Diversity and systematic of the Malacosporea (Myxozoa). Invertebrate Biology 124, 285-295.

Tops, S., Lockwood, B. and Okamura, B. (2006). Temperature-driven proliferation of Tetracapsuloides bryosalmonae in bryozoan hosts portends salmonid declines. Diseases of Aquatic Organisms 70, 227-236.

Tubbs, L. A., Poortenaar, C. W., Sewell, M. A. and Diggles, B. K. (2005). Effects of temperature on fecundity in vitro, egg hatching and reproductive development of Benedenia seriolae and Zeuxapta seriolae (Monogenea) parasitic on yellowtail kingfish Seriola lalandi. International Fournal for Parasitology 35, 315-327.

Yin, J. L., Shackel, N. A., Zekry, A., McGuinness, P. H., Richards, C., Van Der Putten, K., McCaughan, G. W., Eris, J. M. and Bishop, G. A. (2001). Real-time reverse transcriptase-polymerase chain reaction (RT-PCR) for measurement of cytokine and growth factor mRNA expression with fluorogenic probes or SYBR Green I. Immunology and Cell Biology 79, 213-221. 